Check for updates

Cite this: RSC Adv., 2017, 7, 30990

Received 2nd March 2017

Accepted 6th June 2017

DOI: $10.1039 / c 7 r a 02594 g$

rsc.li/rsc-advances

\section{Catalytic hydrodeoxygenation of anisole over nickel supported on plasma treated alumina-silica mixed oxides}

\begin{abstract}
Hamed Taghvaei, ${ }^{\text {ac }}$ Mohammad Reza Rahimpour (D)*ab and Peter Bruggeman ${ }^{\mathrm{c}}$
Hydrodeoxygenation (HDO) of anisole, a representative of lignin-derived bio oil, was investigated on $\mathrm{SiO}_{2}-$ $\mathrm{Al}_{2} \mathrm{O}_{3}$ supported $\mathrm{Ni}$ nano-particles at low hydrogen pressure. Plasma was used for the surface modification of the support. The supports and catalysts were characterized by $\mathrm{N}_{2}$ physisorption, FT-IR spectroscopy, Temperature Program Desorption of ammonia ( $\mathrm{NH}_{3}$-TPD), X-ray diffraction (XRD), field emission scanning electron microscopy (FESEM) and transmission electron microscopy (TEM). The results showed that the plasma treatment improved both the $\mathrm{SiO}_{2}-\mathrm{Al}_{2} \mathrm{O}_{3}$ surface characteristics and pore structure. The catalyst with a plasma treated support had a higher dispersion and smaller $\mathrm{NiO}$ particle size, leading to an improved hydrodeoxygenation activity and product selectivity. Phenol and benzene were the major products of anisole HDO. Demethylation, hydrodeoxygenation and transalkylation reactions are the main chemical reactions for anisole upgrading using the $\mathrm{Ni} / \mathrm{Al}_{2} \mathrm{O}_{3}-\mathrm{SiO}_{2}$ catalyst. Compared to the untreated catalyst, the plasma treated $\mathrm{Ni} / \mathrm{Al}_{2} \mathrm{O}_{3}-\mathrm{SiO}_{2}$ catalyst gives higher anisole conversion at atmospheric pressure by which valuable products were obtained with higher selectivity.
\end{abstract}

\section{Introduction}

Flash pyrolysis of lignin followed by upgrading of the produced bio-oil is a potential approach for $\mathrm{CO}_{2}$ neutral fuel production. ${ }^{1}$ The upgrading step is required since the produced bio-oil from flash pyrolysis contains a high oxygen content (10-45 wt\%) compared to crude oil. ${ }^{2-5}$ A high oxygen content hinders the miscibility of bio-oil with petroleum derived fuels..$^{6-8}$ Moreover, it reduces the heating value and increases the viscosity of bio-oil. ${ }^{9-11}$

Hydrogen plays a key role in the hydrodeoxygenation reaction for oxygen removal from lignin derived bio-oil. Hydrodeoxygenation is the most common upgrading route but is costly due to the large consumption of hydrogen and requires high pressures. ${ }^{12,13}$ At high hydrogen pressure, undesired ring saturated products are generated via unwanted hydrogenation ${ }^{\mathbf{1 4}}$ which leads to decrease in octane number and prevents the direct utilization of the upgraded bio-oil.

Moreover, the use of hydrogen leads to other concerns including (1) hydrogen leakage and ignition at relatively low temperature (2) production of greenhouse gases in many hydrogen production processes used and (3) hydrogen production cost and economy. ${ }^{15}$

\footnotetext{
${ }^{a}$ Department of Chemical Engineering, Shiraz University, Shiraz 71345, Iran. E-mail: rahimpor@shirazu.ac.ir; mrahimpour@ucdavis.edu; Fax: +98-711-6287294; Tel: +98-711-2303071

${ }^{b}$ Department of Chemical Engineering, University of California, Davis, CA 95616, USA ${ }^{c}$ Department of Mechanical Engineering, College of Science and Engineering, University of Minnesota, Minneapolis, MN 55455, USA
}

To date, only few studies on bio-oil hydrodeoxygenation (HDO) at atmospheric pressure have been reported. A possible solution that can enable a reduction of the hydrogen pressure is the synthesis of effective bifunctional hydrodeoxygenation catalysts which combines supports with acidic nature ${ }^{\mathbf{1 3}}$ and metal centers with hydrodeoxygenation (HDO) activity, such as Ni. ${ }^{16,17}$ In 2015 Sankaranarayanan et al. ${ }^{18}$ reported that the combination of $\mathrm{Ni}$ with acidic support showed a high performance for HDO of methoxyl-phenyl containing compounds. The catalytic hydrodeoxygenation of lignin derived bio-oil has recently been reviewed in ref. 9 .

Various approaches have been proposed to improve catalyst properties and characteristics as another solution for improving HDO in term of hydrogen pressure. Among these approaches, non-thermal plasma treatment has attracted a lot of attention due to its low temperature operation, simplicity and short processing time. ${ }^{19-24}$ The plasma treatment of catalysts has recently been reviewed in our published article. ${ }^{25}$ However, the effect of this surface modification method in HDO reaction is not reported.

Conventional hydrotreating catalysts are the most widely investigated catalyst for HDO reactions. ${ }^{26}$ Among them, silicaalumina supported Ni catalysts are commonly used for hydrodesulfurization (HDS) and hydroprocessing of heavy oil. However, only few works ${ }^{27}$ have been devoted to illustrate the activity of this catalyst in HDO reactions of lignin derived biooil. Generally, the amorphous $\mathrm{SiO}_{2}-\mathrm{Al}_{2} \mathrm{O}_{3}$ support has been used for hydroprocessing catalysts due to its favorable acidity due to the presence of both Brønsted and Lewis acid sites. 
Interestingly, the acidity obtained by a combination of silica and alumina is higher than that of individual alumina or silica. $^{28}$

In the present study, plasma modified $\mathrm{SiO}_{2}-\mathrm{Al}_{2} \mathrm{O}_{3}$ supported $\mathrm{Ni}$ was used as catalyst for HDO reactions. The principal aim is to decrease the hydrogen pressure of the HDO process. The effect of the plasma treatment on the characteristics of the catalyst and its performance as a HDO catalyst is investigated. Anisole was used as model compound of lignin-derived bio-oil since anisole, as one of the major component of bio-oil, contains a methoxy-phenyl group..$^{29-32}$

\section{Experimental methods}

\subsection{Materials}

Aluminum tri-sec-butylate (97\%), tetraethyl orthosilicate (TEOS) $(98 \%)$ and nickel nitrate hexahydrate $\left(\mathrm{Ni}\left(\mathrm{NO}_{3}\right)_{2} \cdot 6 \mathrm{H}_{2} \mathrm{O}\right)$ were used as the $\mathrm{Al}, \mathrm{Si}$ and Ni precursors, respectively. Acetylacetone (H-acac) and $n$-butanol were used as the complexing agent and solvent, respectively. All chemicals were purchased from Merck and used without further purification. Hydrogen, nitrogen and argon were used with purity of $99.999 \%$ as feed, carrier gas in the catalytic reactor and carrier gas in the plasma system, respectively. Anisole (99\% purity) was used in this work as a reactant.

\subsection{Support preparation}

In this study, silica-alumina mixed oxides $(\mathrm{Si} / \mathrm{Al}=1)$ were used as a support and prepared by a sol-gel method..$^{33}$ A typical synthesis procedure is as follows. Appropriate amounts of TEOS and aluminum tri-sec-butylate were dissolved in $n$-butanol and the solution was heated to $60{ }^{\circ} \mathrm{C}$ while stirring. When the solution was well mixed and became clear, H-acac was added. The solution was cooled down to ambient temperature and subsequently hydrolyzed with deionized water. The final solution was stirred until a transparent gel was formed. After drying for $2 \mathrm{~h}$ at $110{ }^{\circ} \mathrm{C}$ the sample was calcined at $500{ }^{\circ} \mathrm{C}$ for $5 \mathrm{~h}$. The obtained product is named $\mathrm{Al}_{2} \mathrm{O}_{3}-\mathrm{SiO}_{2}$ throughout the paper.

In the second step, a part of the synthesized support was treated in a glow discharge plasma. A schematic diagram of the plasma device is shown in Fig. 1. The plasma was generated in a pyrex cylinder with a length of $30 \mathrm{~cm}$ and an inner diameter of $7 \mathrm{~cm}$. Two circular stainless still electrodes were placed in the chamber at a distance of $10 \mathrm{~cm}$ and connected to DC high voltage power supply and ground, respectively. All impurities were washed using deionized water and acetone. $\mathrm{Al}_{2} \mathrm{O}_{3}-\mathrm{SiO}_{2}$ powder was placed on a pyrex glass and positioned in the positive column of the plasma discharge. A 2-stage direct drive oil rotary vacuum pump (Uniweld HVP12) was used to evacuate the chamber. Ar was used as a plasma forming gas. The flow rate was controlled by means of a mass flow controller and adjusted at $20 \mathrm{~mL} \min ^{-1}$. The inside pressure was measured by a vacuum gauge and kept constant at $100 \mathrm{~Pa}$. The catalyst was treated by a plasma operating at voltage of $2 \mathrm{kV}$ and a current of $150 \mathrm{~mA}$. Samples were treated for $30 \mathrm{~min}$ and $60 \mathrm{~min}$ by the

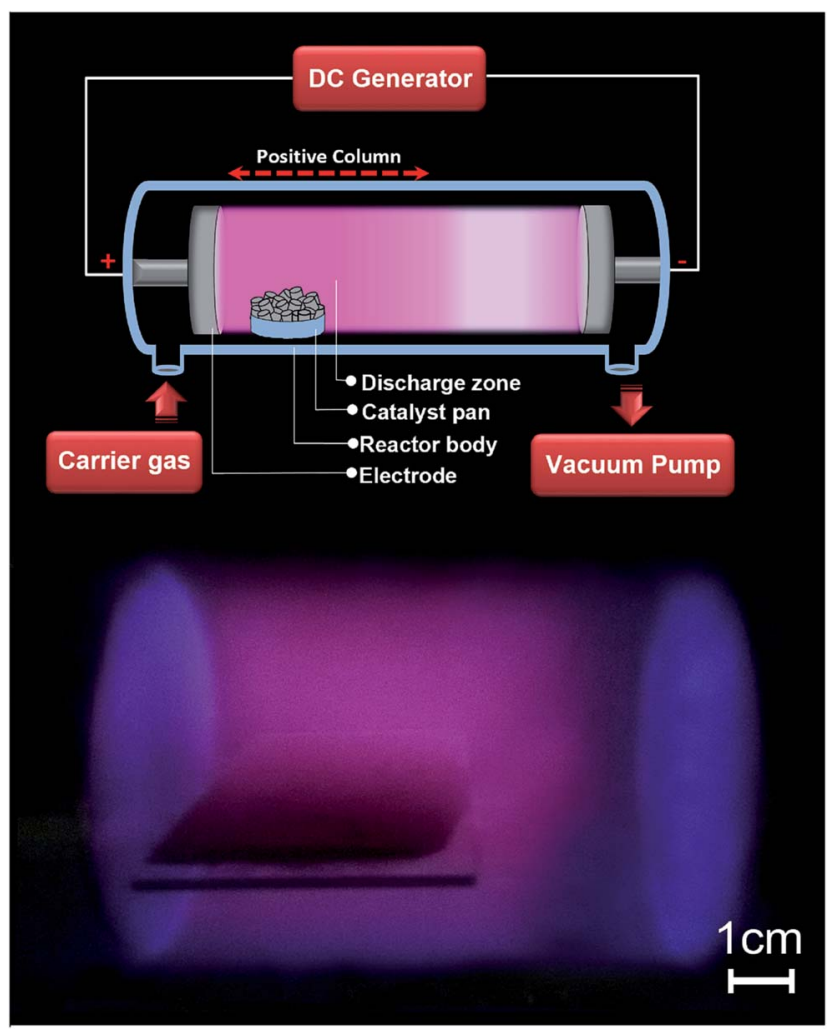

Fig. 1 Schematic of glow discharge plasma reactor used for modification of $\mathrm{Al}_{2} \mathrm{O}_{3}-\mathrm{SiO}_{2}$.

plasma and the resulting powder is referred to as $\mathrm{Al}_{2} \mathrm{O}_{3}$ $\mathrm{SiO}_{2}(\mathrm{P} 30)$ and $\mathrm{Al}_{2} \mathrm{O}_{3}-\mathrm{SiO}_{2}(\mathrm{P} 60)$ respectively.

\subsection{Catalyst preparation}

$\mathrm{Ni} / \mathrm{Al}_{2} \mathrm{O}_{3}-\mathrm{SiO}_{2}$ and $\mathrm{Ni} / \mathrm{Al}_{2} \mathrm{O}_{3}-\mathrm{SiO}_{2}$ (P60) catalysts with $10 \mathrm{wt} \%$ nickel loading were synthesized by incipient wetness impregnation using an aqueous solution of nickel nitrate hexahydrate $\left(\mathrm{Ni}\left(\mathrm{NO}_{3}\right)_{2} \cdot 6 \mathrm{H}_{2} \mathrm{O}\right)$. The aqueous mixture was stirred for $12 \mathrm{~h}$ at room temperature. The solution was heated to $80{ }^{\circ} \mathrm{C}$ to remove water and subsequently placed in an oven at $110^{\circ} \mathrm{C}$ for $2 \mathrm{~h}$. The resulting samples were calcined at $550{ }^{\circ} \mathrm{C}$ for $4 \mathrm{~h}$ to obtain final catalyst.

\subsection{Characterization of the catalysts}

The structural characteristics of the samples were analyzed by X-ray diffraction (XRD) using a Bruker-AXS (Siemens) D5005 diffractometer with a $\mathrm{Cu} \mathrm{K} \alpha(k=0.15406 \mathrm{~nm})$ radiation source operated at $40 \mathrm{~mA}$ and $45 \mathrm{kV}$. XRD diffraction spectra were obtained between $10-70^{\circ}$ with a step size of $0.04^{\circ}$ and a counting time of $1.5 \mathrm{~s}$. Fourier Transform Infrared Spectroscopy (BRUKER EQUINOX 55) was carried out in the range of 400$4000 \mathrm{~cm}^{-1}$ wave number. Temperature-programmed desorption of ammonia ( $\mathrm{NH}_{3}$-TPD) was performed on a chemisorption analyzer (Quantachrome ChemBet).

$\mathrm{N}_{2}$ physisorption was performed by an automatic adsorption analyzer (ASAP 2020) to obtain the $\mathrm{N}_{2}$ adsorption-desorption isotherms at $77 \mathrm{~K}$ and to measure textural properties (specific 
surface area, average pore diameter and pore volume) of samples. Before the measurement, the samples were degassed at $300{ }^{\circ} \mathrm{C}$ for $6 \mathrm{~h}$ under vacuum to remove impurities. The Brunauer-Emmett-Teller (BET) method was used to evaluate the specific surface area of samples, while the pore volume and average pore diameter were calculated with the Barrett-JoynerHalenda (BJH) method.

The topography and particle size of the catalyst was characterized by Field Emission Scanning Electron Microscopy (FESEM), which was equipped with a Mira3 microscope and an energy-dispersive X-ray spectrometer (EDS).

The morphologies of the catalyst and Ni size were characterized using transmission electron microscopy (TEM). A FEI Tecnai T12 TEM operated at $200 \mathrm{kV}$ was used. The sample was prepared by depositing a drop of water suspension of fine powder onto a copper grid coated with carbon.

\subsection{Experimental setup for catalytic activity measurements}

The catalytic reaction experiments were conducted in the gas phase using a fixed bed tubular flow reactor (with an inside diameter of $9 \mathrm{~mm}$ ) at a temperature of $400{ }^{\circ} \mathrm{C}$ and atmospheric pressure. Liquid anisole at room temperature was fed by an HPLC pump with $0.02 \mathrm{~mL} \mathrm{~min}^{-1}$ flow rate into the preheating zone to heat it to a temperature of $150{ }^{\circ} \mathrm{C}$. The vaporized anisole was mixed with the gas stream consisting of a mixture of $\mathrm{N}_{2}$ and $\mathrm{H}_{2}$ and fed to the reactor. The flow rate of $\mathrm{N}_{2}$ and $\mathrm{H}_{2}$ was adjusted at $10 \mathrm{~L} \mathrm{~h}^{-1}$ for each gas (room temperature and atmospheric pressure) using mass flow controllers to obtain $\mathrm{a}_{2}$ to anisole molar ratio of 40 . Liquid products were collected from a condenser which was placed at the reactor outlet.

Fresh catalyst, about $1 \mathrm{~g}$ with a particle diameter of $0.25-0.30$ $\mathrm{mm}$ was used for each experiment. Before the reaction, the catalysts were reduced for $1 \mathrm{~h}$ in the reactor with pure hydrogen at a flow rate of $6 \mathrm{~L} \mathrm{~h}^{-1}$ at $500{ }^{\circ} \mathrm{C}$. The value of the weight hourly space velocity (WHSV) was 1.2 ( $\mathrm{g}$ of anisole)/(g of catalyst $\times \mathrm{h}$ ). All experiments typically lasted $3 \mathrm{~h}$ of continuous operation and liquid products were collected every $30 \mathrm{~min}$.

In order to analyze the products, a gas chromatograph (GC112A) using a SGE-BPX5 capillary column and FID detector was employed. $2 \mu \mathrm{L}$ of each sample was injected into the GC. The major components were also detected by a GC-MS (Shimadzu QP-5050, Kyoto, Japan).

The anisole conversion percentage and product selectivity $\left(S_{\mathrm{i}}\right)$ were defined as follows:

$$
\begin{gathered}
\text { Anisole conversion }(\%)=\frac{C_{\text {in }}-C_{\text {out }}}{C_{\text {in }}} \times 100 \\
\mathrm{Si}=\frac{\text { produced moles of } \mathrm{i} \text { component }}{\text { consumed moles of anisole }}
\end{gathered}
$$

with $C_{\text {in }}$ and $C_{\text {out }}$ the input and output concentrations of anisole in the reactor, respectively.

The influence of external mass transfer limitation was negligible under the experimental conditions since variation of catalyst mass and reactant flow at stable WHSV did not affect the conversion. Moreover, no variation of anisole conversion was observed by reducing the catalyst size which confirmed the insignificancy of internal mass transfer limitation.

\section{Results and discussion}

\subsection{Morphology of plasma-treated $\mathrm{Al}_{2} \mathrm{O}_{3}-\mathrm{SiO}_{2}$}

The textural properties of the untreated and plasma treated support are compared by nitrogen physisorption measurement. The $\mathrm{N}_{2}$ adsorption-desorption isotherms and pore size distributions of the $\mathrm{Al}_{2} \mathrm{O}_{3}-\mathrm{SiO}_{2}, \mathrm{Al}_{2} \mathrm{O}_{3}-\mathrm{SiO}_{2}$ (P30) and $\mathrm{Al}_{2} \mathrm{O}_{3}-\mathrm{SiO}_{2}$ (P60) supports are shown in Fig. 2. The BET surface area, pore volume and average pore diameter of the samples are listed in Table 1.

The $\mathrm{N}_{2}$ adsorption-desorption isotherm of the untreated and plasma treated supports are classified as type IV isotherms of mesoporous materials according to the IUPAC classification. ${ }^{34}$ The mesoporous alumina-silica mixed oxides show high specific surface area of $517 \mathrm{~m}^{2} \mathrm{~g}^{-1}$, with a small enhancement after plasma treatment which is in consistent with the results in other literature. ${ }^{25}$ As shown in Fig. 2 the hysteresis loops of the plasma treated supports are shifted to lower $P / P_{0}$ values. The reason is ascribe to the fragmentation of support particles as
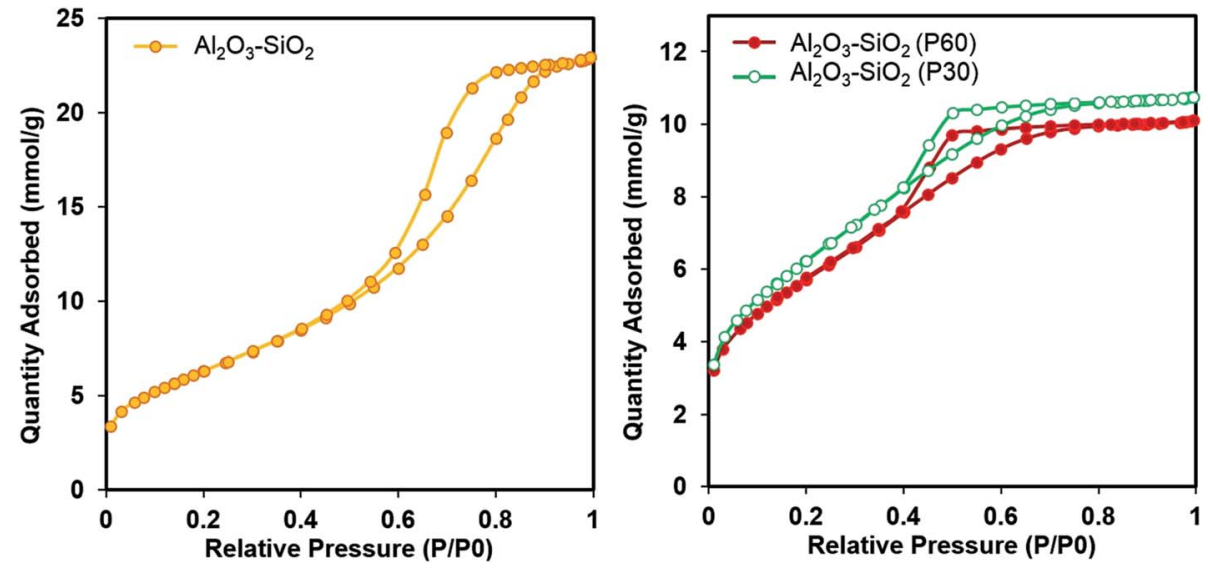

Fig. $2 \mathrm{~N}_{2}$ adsorption-desorption isotherms of untreated and plasma treated supports. 
Table 1 Textural properties of the supports and the catalysts

\begin{tabular}{llll}
\hline Samples & $\begin{array}{l}S_{\mathrm{BET}} \\
\left(\mathrm{m}^{2} \mathrm{~g}^{-1}\right)\end{array}$ & $\begin{array}{l}\text { Pore volume }^{a} \\
\left(\mathrm{~cm}^{3} \mathrm{~g}^{-1}\right)\end{array}$ & $\begin{array}{l}\text { Pore size }^{a} \\
(\mathrm{~nm})\end{array}$ \\
\hline $\mathrm{Al}_{2} \mathrm{O}_{3}-\mathrm{SiO}_{2}$ & 517.3 & 0.82 & 4.94 \\
$\mathrm{Al}_{2} \mathrm{O}_{3}-\mathrm{SiO}_{2}(\mathrm{P} 30)$ & 532 & 0.41 & 3.29 \\
$\mathrm{Al}_{2} \mathrm{O}_{3}-\mathrm{SiO}_{2}(\mathrm{P} 60)$ & 528.4 & 0.43 & 3.23 \\
$10 \% \mathrm{Ni} / \mathrm{Al}_{2} \mathrm{O}_{3}-\mathrm{SiO}_{2}$ & 151.6 & 0.19 & 3.88 \\
$10 \% \mathrm{Ni} / \mathrm{Al}_{2} \mathrm{O}_{3}-\mathrm{SiO}_{2}(\mathrm{P} 60)$ & 171.7 & 0.21 & 2.91 \\
${ }^{a} \mathrm{Calculated}$ by BJH desorption theory. & &
\end{tabular}

a consequence of support surface bombardment by energetic ions and potentially other plasma species.

The obtained results are in accordance with the pore size distributions obtained by $\mathrm{N}_{2}$ physisorption is shown in Fig. 3 . The pore size distribution of the plasma treated $\mathrm{Al}_{2} \mathrm{O}_{3}-\mathrm{SiO}_{2}$ has its maximum between $2-4 \mathrm{~nm}$, with a maximum pore diameter of $3.3 \mathrm{~nm}$. However, untreated samples show a broader pore size distribution in the range of 2-8 $\mathrm{nm}$. Moreover, the maximum of the pore size distribution decreases from $6.2 \mathrm{~nm}$ to $3.7 \mathrm{~nm}$, after plasma treatment.

A narrower mesoporous structure of the plasma treated support has significant influence on impregnated metal particle size and can prevent the agglomeration of the active phase through a geometrical confinement effect which restricts the growth of Ni crystallites during high temperature reaction. ${ }^{35}$ Increasing the plasma treatment time from $30 \mathrm{~min}$ to $60 \mathrm{~min}$ has no significant effects on the nitrogen physisorption.

Fig. 4 displays the surface morphology of the untreated and plasma-treated support. The FESEM graphs show that the plasma treatment has considerable effects both on the morphology and grain sizes of the support.

The spherical particles of plasma treated support has smaller diameter with a uniform dispersion. In contrast, the untreated support consists of large particles and shows a comparatively rough surface. These results are consistent with the nitrogen physisorption results.

As mentioned above, the bombardment of the catalytic surface by plasma species and in particularly ions can cause
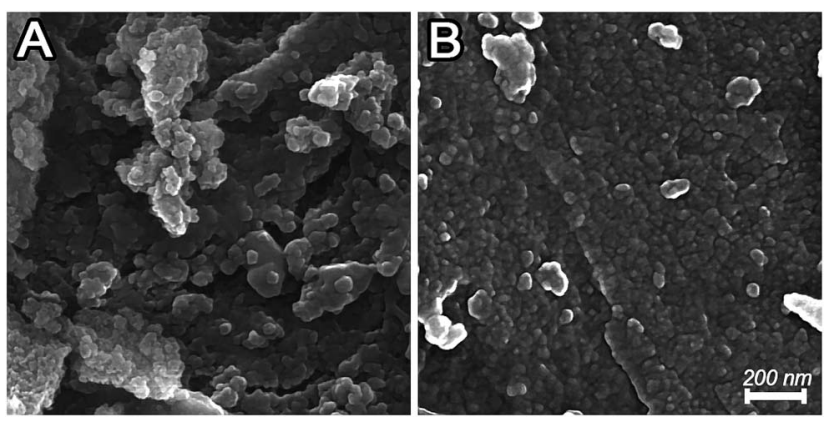

Fig. 4 FESEM images of (A) $\mathrm{Al}_{2} \mathrm{O}_{3}-\mathrm{SiO}_{2}$ (B) $\mathrm{Al}_{2} \mathrm{O}_{3}-\mathrm{SiO}_{2}(\mathrm{P} 60)$.

fragmentation of support particles. Moreover, when objects such as the support are inserted in the plasma they tend to be charged negatively by the energetic electrons in the plasma. This leads to the formation of a sheath between the support and the bulk plasma with local high electric fields. This charge distribution on a rough surface can cause repulsive Coulomb force between support particles and is suggested to potentially enhance elongation, distortion or fragmentation by the plasma. ${ }^{36}$

\subsection{FTIR analysis}

FTIR spectra of plasma treated and untreated $\mathrm{Al}_{2} \mathrm{O}_{3}-\mathrm{SiO}_{2}$ are shown in Fig. 5. All samples have similar peak positions and there is no significant difference between the FTIR spectra of treated and untreated support. All samples show absorption peaks around $2900-3800$ and $1050 \mathrm{~cm}^{-1}$ which are related to $\mathrm{OH}$ of $(\mathrm{Si} / \mathrm{Al}) \mathrm{O}_{4}$ units of the $\mathrm{Al}_{2} \mathrm{O}_{3}-\mathrm{SiO}_{2}$ and physically adsorbed water molecules. Moreover, the broad band at around $600-900 \mathrm{~cm}^{-1}$ is corresponding to stretching vibrations modes of $\mathrm{X}-\mathrm{O}, \mathrm{O}-\mathrm{X}-\mathrm{O}$ and $\mathrm{X}-\mathrm{O}-\mathrm{X}$ bonds, where $\mathrm{X}$ represents $\mathrm{Si}$ and $\mathrm{Al}$, and $\mathrm{O}$ is the atom of oxygen. The observed bands at 2925-2940 and 2854-2877 $\mathrm{cm}^{-1}$ for all samples are attributed to the $-\mathrm{CH}_{2}$ stretching mode of atmospheric hydrocarbons on the surface of the support.

\subsection{Temperature program desorption of ammonia ( $\left.\mathrm{NH}_{3}-\mathrm{TPD}\right)$}

The acidity of $\mathrm{Al}_{2} \mathrm{O}_{3}-\mathrm{SiO}_{2}$ after plasma treatment is compared with the untreated sample. $\mathrm{NH}_{3}$-TPD was performed to
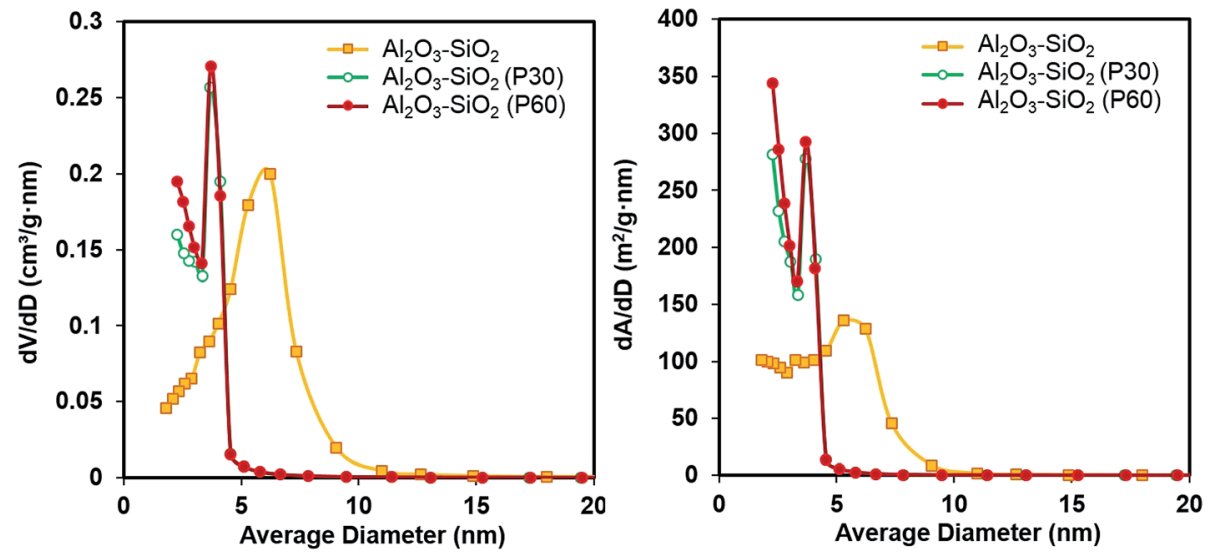

Fig. 3 Pore size distribution of untreated and plasma treated supports 


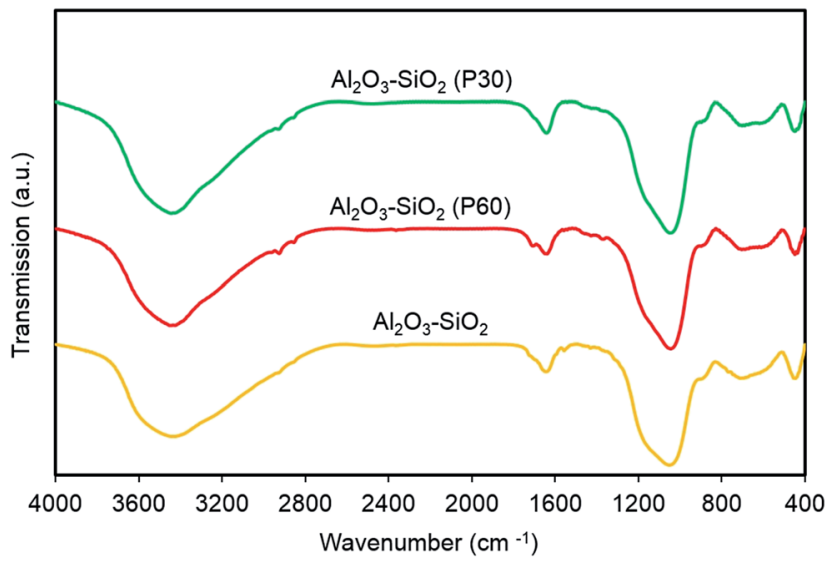

Fig. 5 FTIR spectra of plasma treated and untreated support. The spectra of $\mathrm{Al}_{2} \mathrm{O}_{3}-\mathrm{SiO}_{2} \mathrm{P} 30$ and $\mathrm{P} 60$ are shifted for clarity.

characterize the distribution of weak and strong acid. The lowand high-temperature peaks represent the weak acid and strong acid sites, respectively. As shown in Fig. 6, the weak acid sites decrease after plasma treatment while the strong acid sites increase. This can be attributed to diffusion of $\mathrm{Al}$ from aluminum oxides (Al-O-Al) or isolated aluminum grafted to silica into the silica network (Al-O-Si), which induces the Brønsted acidity. ${ }^{37}$ Indeed, larger number of aluminum atoms have been tetrahedrally coordinated into the silica network. ${ }^{37,38}$ Previous studies showed that supports with a strong acidity are crucial for the catalytic hydrodeoxygenation reaction. ${ }^{39}$ Therefore, besides improving textural properties, plasma treatment can improve the HDO reaction through increasing strong acid functionality.

\subsection{X-ray diffraction (XRD) of the catalysts}

Fig. 7 shows the XRD patterns of the $\mathrm{Al}_{2} \mathrm{O}_{3}-\mathrm{SiO}_{2}, \mathrm{Ni} / \mathrm{Al}_{2} \mathrm{O}_{3}-\mathrm{SiO}_{2}$ and $\mathrm{Ni} / \mathrm{Al}_{2} \mathrm{O}_{3}-\mathrm{SiO}_{2}(\mathrm{P} 60)$. The amorphous alumina-silica can be observed by a broad peak in the $15-35^{\circ} 2 \theta$ range. Diffraction peaks at $37.2^{\circ}, 43.3^{\circ}$, and $62.9^{\circ}(2 \theta)$ correspond to the (111), (200), and (220) planes of NiO phase and seem to be present

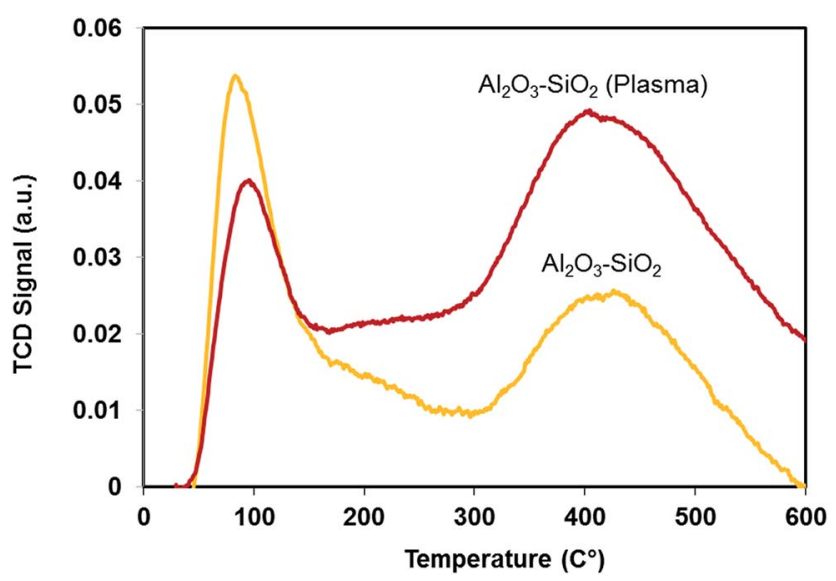

Fig. $6 \mathrm{NH}_{3}$-TPD profiles of plasma treated and untreated support.

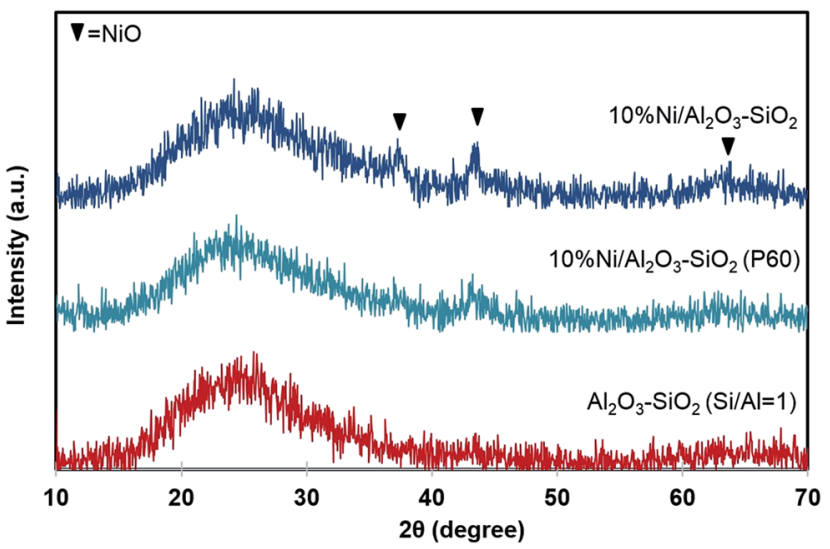

Fig. 7 XRD spectra of support and catalysts. The spectra of $\mathrm{Al}_{2} \mathrm{O}_{3}-$ $\mathrm{SiO}_{2} \mathrm{P} 60$ and $10 \% \mathrm{Ni} / \mathrm{Al}_{2} \mathrm{O}_{3}-\mathrm{SiO}_{2}$ are shifted for clarity.

although the intensities are almost at the noise level. These poor intensities suggesting that $\mathrm{NiO}$ crystal size exists either in small size or they are well dispersed on a high surface area of the mesostructure support. ${ }^{28}$ The small crystallite size of NiO can be due to strong interaction between $\mathrm{NiO}$ and support. ${ }^{40}$ Weaker NiO peaks are observed for $\mathrm{Ni} / \mathrm{Al}_{2} \mathrm{O}_{3}-\mathrm{SiO}_{2}$ (P60) compared to $\mathrm{Ni} / \mathrm{Al}_{2} \mathrm{O}_{3}-\mathrm{SiO}_{2}$, indicating slightly smaller crystal size and higher dispersion for NiO.

\subsection{TEM studies on the catalyst}

Transmission electron microscopy (TEM) images of NiO supported nanocatalysts, shown in Fig. 8, revealing a smaller size of nickel particles in the case of $\mathrm{Ni} / \mathrm{Al}_{2} \mathrm{O}_{3}-\mathrm{SiO}_{2}$ (P60) compared to the $\mathrm{Ni} / \mathrm{Al}_{2} \mathrm{O}_{3}-\mathrm{SiO}_{2}$ nanocatalyst. This result is consistent with the observed small NiO diffraction peaks with XRD.

Some nickel oxide agglomerates up to $17 \mathrm{~nm}$ in size can be clearly observed for the $\mathrm{Ni} / \mathrm{Al}_{2} \mathrm{O}_{3}-\mathrm{SiO}_{2}$ catalyst. In contrast, the plasma treated catalysts contain Ni particles with smaller sizes and more homogeneous distribution. Nanoparticles of around 1-10 nm are observed for the $\mathrm{Ni} / \mathrm{Al}_{2} \mathrm{O}_{3}-\mathrm{SiO}_{2}$ (P60) catalyst.

The interaction of ions with the support surface could improve the kinetics of metal particle nucleation and crystal growth by generation of defects which can enhance the formation of seed crystals and the rate of metal particle nucleation. ${ }^{19,41}$ In addition, the narrower mesoporous structure of
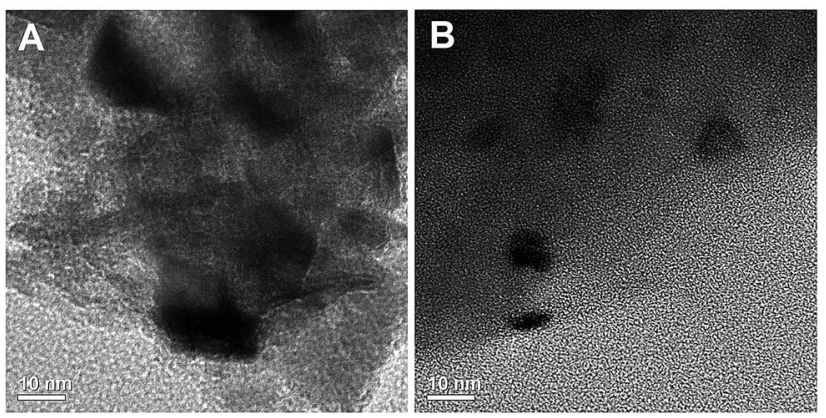

Fig. $8 \mathrm{TEM}$ images of (A) $\mathrm{Ni} / \mathrm{Al}_{2} \mathrm{O}_{3}-\mathrm{SiO}_{2}$ (B) Ni/Al $\mathrm{O}_{3}-\mathrm{SiO}_{2}(\mathrm{P} 60)$. 
plasma treated support can have a significant influence on metal particle size due to geometrical confinement ${ }^{35}$ and lead to better impregnation of the nickel on the support. Indeed, the narrower pore size of plasma treated support can prevent the growth and aggregation of nickel particles. The confined nickel particles in the plasma treated catalyst can be confined by a smaller drop in pore volume of plasma treated catalyst after impregnation of nickel. $\mathrm{N}_{2}$ physisorption results (Table 1) show that the pore volume of the plasma treated catalyst drops by $51 \%$ after impregnation of nickel on the support, while this value is $76 \%$ in the case of untreated catalyst.

Therefore, less pore plugging occurs in the $\mathrm{Ni} / \mathrm{Al}_{2} \mathrm{O}_{3}-\mathrm{SiO}_{2}$ (P60) sample due to the smaller $\mathrm{NiO}$ particles and leads to a relatively higher surface area of $\mathrm{Ni} / \mathrm{Al}_{2} \mathrm{O}_{3}-\mathrm{SiO}_{2}$ (P60) sample in comparison with $\mathrm{Ni} / \mathrm{Al}_{2} \mathrm{O}_{3}-\mathrm{SiO}_{2}$ (Table 1).

\subsection{FESEM and EDS dot mapping analysis}

The existance of different elements ( $\mathrm{Ni}, \mathrm{Si}$ and $\mathrm{Al}$ ) and also, their distribution in the structure of the nanocatalyst are confirmed by EDX dot-mapping. Fig. 9 shows the elemental mapping of the $\mathrm{Ni} / \mathrm{Al}_{2} \mathrm{O}_{3}-\mathrm{SiO}_{2}$ (P60) nanocatalyst. All the elements used for the catalyst preparation ( $\mathrm{Ni}, \mathrm{Al}$ and $\mathrm{Si}$ ) can be seen in the EDS analysis. The EDX data suggests that highly homogeneous and well-dispersed nanocatalyst particles are obtained by using plasma treated supports. No sintering or particle growth was observed in the Ni particles. These findings are consistent with the TEM and XRD results.

Moreover, an intertwined dispersion of $\mathrm{Ni}, \mathrm{Si}$ and $\mathrm{Al}$ is observed in the NiO supported plasma treated $\mathrm{Al}_{2} \mathrm{O}_{3}-\mathrm{SiO}_{2}$. This represents successful preparation of alumina and silica mixed oxides. In addition, the synergism effect of active sites and acid sites for HDO reaction can be improved.

\subsection{Catalytic activity}

Fig. 10 shows the variation of conversion for the $\mathrm{Ni} / \mathrm{Al}_{2} \mathrm{O}_{3}-\mathrm{SiO}_{2}$ (P60) and $\mathrm{Ni} / \mathrm{Al}_{2} \mathrm{O}_{3}-\mathrm{SiO}_{2}$ nanocatalysts over $300 \mathrm{~min}$ for time-onstream experiments. In the blank test without catalyst, no anisole conversion is observed under the reaction conditions. As can be seen, conversion remains almost constant during the

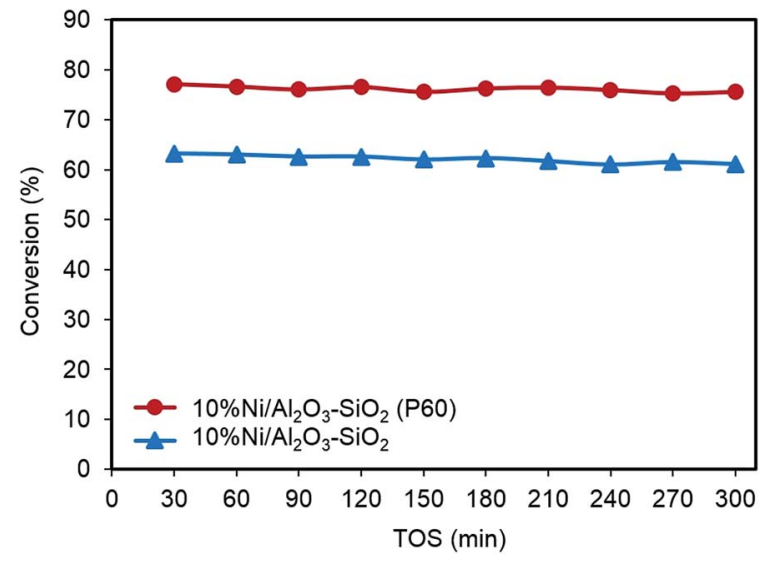

Fig. 10 Time-on-stream behavior of anisole conversion on $\mathrm{Ni} / \mathrm{Al}_{2} \mathrm{O}_{3}-$ $\mathrm{SiO}_{2}$ and $\mathrm{Ni} / \mathrm{Al}_{2} \mathrm{O}_{3}-\mathrm{SiO}_{2}$ (P60) nanocatalysts.

test time. Plasma treated $\mathrm{Al}_{2} \mathrm{O}_{3}-\mathrm{SiO}_{2}$ supported nickel catalyst exhibits higher $\mathrm{HDO}$ activity of anisole compared to the $\mathrm{Ni}$ / $\mathrm{Al}_{2} \mathrm{O}_{3}-\mathrm{SiO}_{2}$. The conversion of anisole increases from $61.1 \%$ to $75.5 \%$ when $\mathrm{Ni} / \mathrm{Al}_{2} \mathrm{O}_{3}-\mathrm{SiO}_{2}$ catalyst were replaced with $\mathrm{Ni}$ / $\mathrm{Al}_{2} \mathrm{O}_{3}-\mathrm{SiO}_{2}$ (P60) catalyst. The increased conversion can be attributed to smaller $\mathrm{Ni}$ particle size and a better dispersion of nickel along with higher specific surface area of $\mathrm{Ni} / \mathrm{Al}_{2} \mathrm{O}_{3}-\mathrm{SiO}_{2}$ (P60) compared to $\mathrm{Ni} / \mathrm{Al}_{2} \mathrm{O}_{3}-\mathrm{SiO}_{2}$ nanocatalyst as shown in previous sections. The enhancement in the conversion is also believed to be the result of increasing the strong acid sites of support after plasma treatment. ${ }^{39,42}$ The acid site on support would further affect the interaction between reactant and support material. Lin et al. employed the chemisorption of guaiacol and proved that the higher acid strength had stronger bonding with the model compound supports. ${ }^{43}$

Phenol, methylphenols and benzene are the major products of anisole hydrodeoxygenation over both catalysts as shown in Fig. 11. A reaction network to major and minor products is shown in Fig. 12. The selectivity of phenol reaches almost $37.1 \%$ in the case of the $\mathrm{Ni} / \mathrm{Al}_{2} \mathrm{O}_{3}-\mathrm{SiO}_{2}$ (P60) and it is close to $34.4 \%$ when $\mathrm{Ni} / \mathrm{Al}_{2} \mathrm{O}_{3}-\mathrm{SiO}_{2}$ is used. This monooxygenated product is a result of breaking the $\mathrm{C}_{6} \mathrm{H}_{5} \mathrm{O}-\mathrm{CH}_{3}$ bond which is the weakest
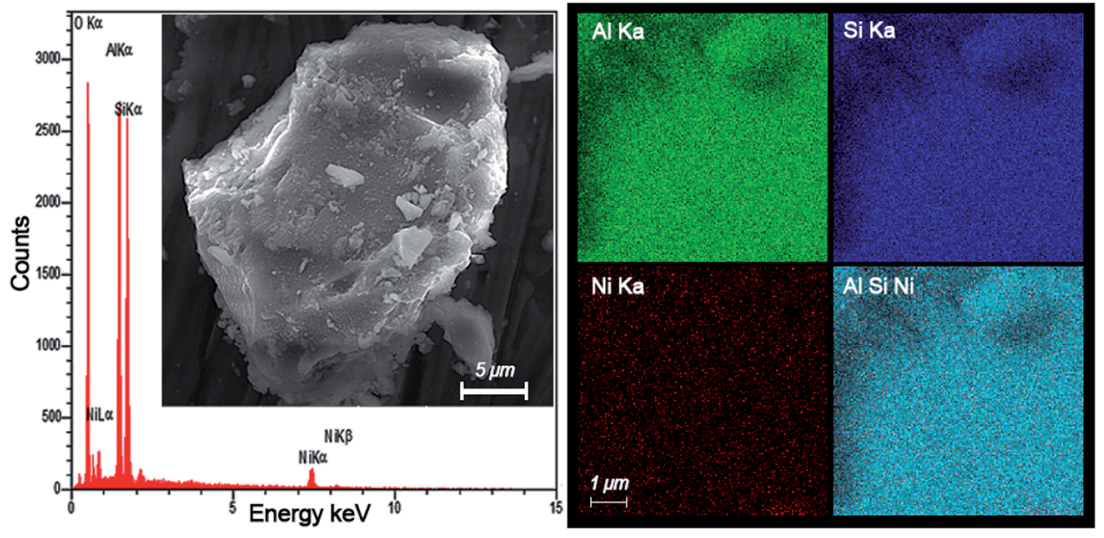

Fig. 9 FESEM and EDX mapping of the $\mathrm{Ni} / \mathrm{Al}_{2} \mathrm{O}_{3}-\mathrm{SiO}_{2}(\mathrm{P} 60)$ nanocatalyst. 


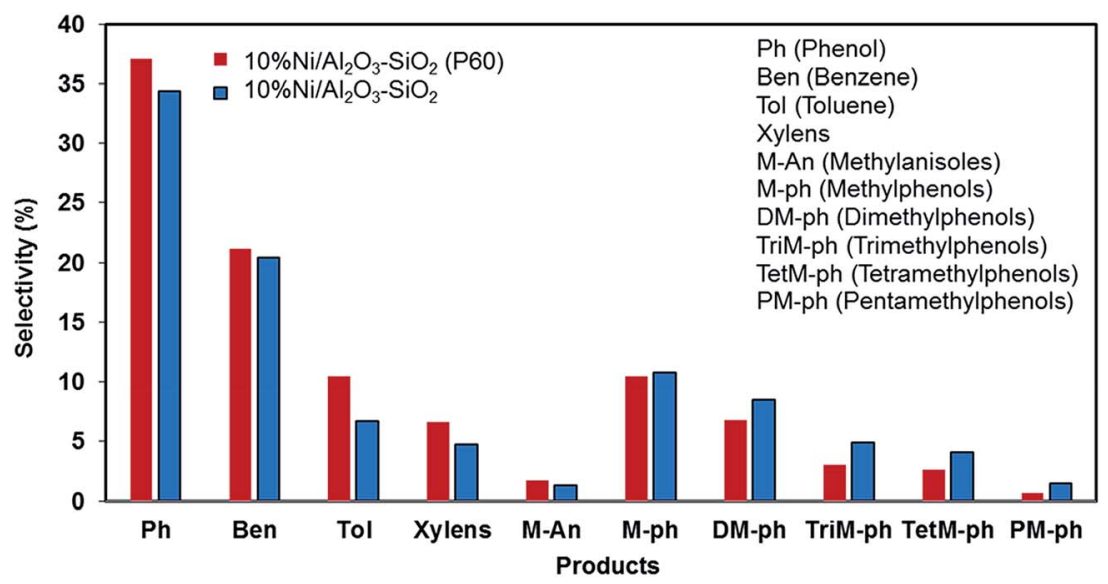

Fig. 11 Product selectivity of anisole conversion, TOS $=30 \mathrm{~min}$.

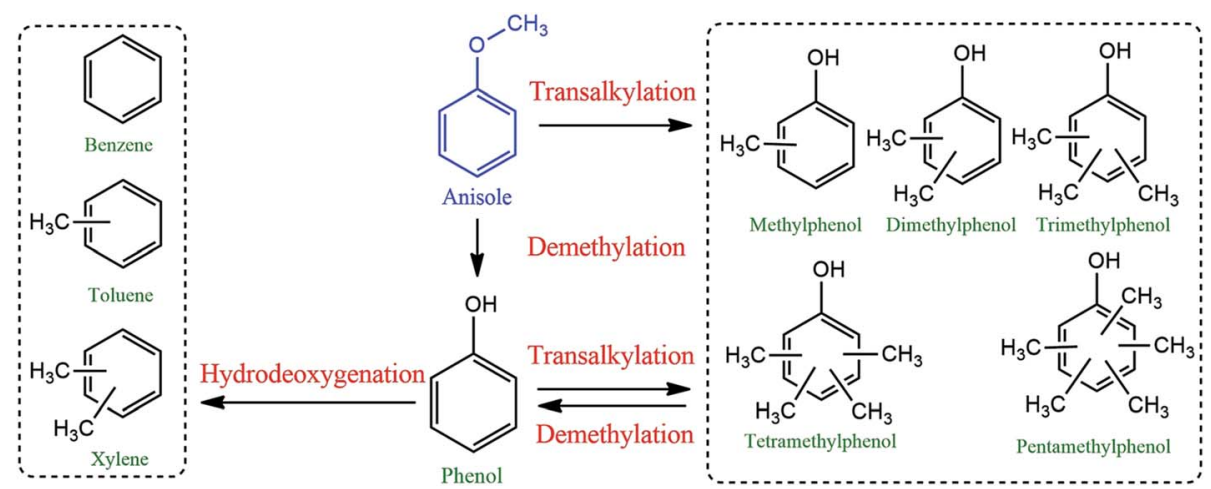

Fig. 12 Reaction network to major and minor products.

bond in the chemical structure of anisole. Therefore, the rate of anisole demethylation to phenol is higher than other reactions.

The production of benzene is also significant for both catalysts, especially for $\mathrm{Ni} / \mathrm{Al}_{2} \mathrm{O}_{3}-\mathrm{SiO}_{2}$ (P60), which shows a selectivity of $21.2 \%$ toward this valuable deoxygenated product. Benzene could be produce through hydrodeoxygenation of phenol.

In addition to benzene, a significant amount of methyl substituted phenols are also produced since the $\mathrm{C}_{\text {aromatic }}-\mathrm{H}$ bond can break easier than the $\mathrm{C}_{6} \mathrm{H}_{5}-\mathrm{OH}$ bond..$^{15}$ The production of methyl substituted compounds like methylphenols and dimethylphenols result from the transalkylation reaction. However, higher selectivity of benzene was achieved than methyl substituted phenol products especially in the case of the plasma treated catalyst. This result can be related to the high hydrodeoxygenation ability of the synthesized catalysts especially in the case of the $\mathrm{Ni} / \mathrm{Al}_{2} \mathrm{O}_{3}-\mathrm{SiO}_{2}$ (P60) catalyst which has smaller NiO particles. This result is consistent with previous results that showed that smaller nickel particles are more favorable for hydrodeoxygenation reactions. ${ }^{16}$ Moreover, the catalytic roles of metal nanoparticles on acidic supports were elucidated using the acid-site-measurement-dependent catalysis results in previous studies, which demonstrated that metaldeposited acidic supports were indispensable to the deoxygenation of oxygenates. ${ }^{44}$
The high amount of strong acid sites in the plasma treated catalyst could also accelerate the production of toluene and xylens through alkylation of benzene ring.

Actually, plasma treatment can have both negative and positive influence on alkylation reaction. On one side, it can reduce the active metal particle size which can result in higher oxygen removal reaction compared to alkylation. ${ }^{\mathbf{4 4}}$ As a result of this effect, methyl substituted phenol products were generated lower than benzene. On the other side, it can enhance the strong acid sites which results in higher alkylation reaction than other reactions. Due to this effect, the generated benzene can convert to toluene and xylens through alkylation of benzene ring.

Interestingly, no ring saturated products are observed which is because the conversion took place at atmospheric pressure.

In summary, the obtained results reveal that promoting the characteristics of $\mathrm{Al}_{2} \mathrm{O}_{3}-\mathrm{SiO}_{2}$ supported nickel catalyst through plasma modification of the support, not only elevated considerably the catalytic activity for HDO, but also increased anisole conversion to more valuable chemicals, such as phenol and benzene at atmospheric pressure. Moreover, considering the formation of desirable products and high conversion at low hydrogen pressure, the $\mathrm{Al}_{2} \mathrm{O}_{3}-\mathrm{SiO}_{2}$ based catalyst was found to be highly appropriate for upgrading of lignin-derived bio-oil. 


\section{Conclusions}

In this study, $\mathrm{Ni}$ supported on $\mathrm{Al}_{2} \mathrm{O}_{3}-\mathrm{SiO}_{2}$ were synthesized by impregnation method have been evaluated for anisole hydrodeoxygenation at atmospheric pressure. Glow discharge plasma treatment was used for modification of support. It is revealed by nitrogen physisorption and SEM that plasma treated support has narrower pore size distribution (2-4 nm), smaller particles and more uniform surface compared to untreated support. These led to smaller NiO particle size, higher surface areas and better distribution of $\mathrm{NiO}$, as evidenced by XRD, nitrogen physisorption, SEM, elemental mapping and TEM measurements. Moreover, the plasma treated catalyst showed higher strong acid sites as shown by $\mathrm{NH}_{3}$-TPD. As a consequence, the catalyst with plasma-treated support showed significantly improved anisole conversion. Demethylation, hydrodeoxygenation and transalkylation reactions take place over the $\mathrm{Ni} / \mathrm{Al}_{2} \mathrm{O}_{3}-\mathrm{SiO}_{2}$ catalyst, suggesting it is a suitable catalyst for upgrading of bio oil in order to attain valuable products at atmospheric pressure.

\section{Acknowledgements}

Parts of the characterization of the catalyst was performed at the University of Minnesota supported by the University of Minnesota.

\section{References}

1 T. Prasomsri, A. T. To, S. Crossley, W. E. Alvarez and D. E. Resasco, Appl. Catal., B, 2011, 106, 204-211.

2 M. Ishikawa, M. Tamura, Y. Nakagawa and K. Tomishige, Appl. Catal., B, 2016, 182, 193-203.

3 H. Taghvaei, M. B. Hosseinzadeh, S. Rezazadeh, M. R. Rahimpour and A. Shariati, Chem. Eng. J., 2015, 281, 227-235.

4 M. B. Hosseinzadeh, S. Rezazadeh, H. R. Rahimpour, H. Taghvaei and M. R. Rahimpour, Chem. Eng. Res. Des., 2015, 104, 296-305.

5 X. Zhang, Q. Zhang, T. Wang, L. Ma, Y. Yu and L. Chen, Bioresour. Technol., 2013, 134, 73-80.

6 H. Taghvaei, M. Kheirollahivash, M. Ghasemi, P. Rostami and M. R. Rahimpour, Energy Fuels, 2014, 28, 2535-2543.

7 H. Taghvaei, M. Kheirollahivash, M. Ghasemi, P. Rostami, B. C. Gates and M. R. Rahimpour, Energy Fuels, 2014, 28, 4545-4553.

8 X. Zhang, L. Chen, W. Kong, T. Wang, Q. Zhang, J. Long, Y. Xu and L. Ma, Energy, 2015, 84, 83-90.

9 M. Saidi, F. Samimi, D. Karimipourfard, T. Nimmanwudipong, B. C. Gates and M. R. Rahimpour, Energy Environ. Sci., 2014, 7, 103.

10 T. N. Pham, D. Shi and D. E. Resasco, Appl. Catal., B, 2014, 145, 10-23.

11 X. Zhang, Q. Zhang, L. Chen, Y. Xu, T. Wang and L. Ma, Chin. J. Catal., 2014, 35, 302-309.

12 A. Sanna, T. P. Vispute and G. W. Huber, Appl. Catal., B, 2015, 165, 446-456.
13 Y. Yang, C. Ochoa-Hernández, V. A. de la Peña O'Shea, P. Pizarro, J. M. Coronado and D. P. Serrano, Appl. Catal., $B, 2014,145,91-100$.

14 T. Prasomsri, M. Shetty, K. Murugappan and Y. RománLeshkov, Energy Environ. Sci., 2014, 7, 2660.

15 H. Taghvaei and M. R. Rahimpour, RSC Adv., 2016, 6, 9836998380.

16 P. M. Mortensen, J.-D. Grunwaldt, P. A. Jensen and A. D. Jensen, Catal. Today, 2016, 259, 277-284.

17 A. B. Dongil, I. T. Ghampson, R. García, J. L. G. Fierro and N. Escalona, RSC Adv., 2016, 6, 2611-2623.

18 T. M. Sankaranarayanan, A. Berenguer, C. OchoaHernández, I. Moreno, P. Jana, J. M. Coronado, D. P. Serrano and P. Pizarro, Catal. Today, 2015, 243, 163172.

19 N. Wang, K. Shen, X. Yu, W. Qian and W. Chu, Catal. Sci. Technol., 2013, 3, 2278.

20 Y. Zhao, Y.-x. Pan, Y. Xie and C.-j. Liu, Catal. Commun., 2008, 9, 1558-1562.

21 Z. Wang and C.-J. Liu, Nano Energy, 2015, 11, 277-293.

22 X. Zhu, P. Huo, Y.-p. Zhang, D.-g. Cheng and C.-j. Liu, Appl. Catal., B, 2008, 81, 132-140.

23 C. Liu, K. Yu, Y. Zhang, X. Zhu, F. He and B. Eliasson, Appl. Catal., B, 2004, 47, 95-100.

24 Y.-X. Pan, C.-J. Liu and P. Shi, J. Power Sources, 2008, 176, 4653.

25 H. Taghvaei, M. Heravi and M. R. Rahimpour, Plasma Processes Polym., 2016, DOI: 10.1002/ppap.201600204.

26 P. M. de Souza, R. C. Rabelo-Neto, L. E. P. Borges, G. Jacobs, B. H. Davis, T. Sooknoi, D. E. Resasco and F. B. Noronha, ACS Catal., 2015, 5, 1318-1329.

27 O. O. Ayodele, F. A. Dawodu, D. Yan, X. Lu, J. Xin and S. Zhang, Renewable Energy, 2016, 86, 943-948.

28 C. Leyva, M. Rana and J. Ancheyta, Catal. Today, 2008, 130, 345-353.

29 X. Zhu, L. L. Lobban, R. G. Mallinson and D. E. Resasco, J. Catal., 2011, 281, 21-29.

30 M. Saidi, P. Rostami, H. R. Rahimpour, M. A. Roshanfekr Fallah, M. R. Rahimpour, B. C. Gates and S. Raeissi, Energy Fuels, 2015, 29, 4990-4997.

31 R. C. Runnebaum, T. Nimmanwudipong, D. E. Block and B. C. Gates, Catal. Sci. Technol., 2012, 2, 113.

32 R. C. Runnebaum, R. J. Lobo-Lapidus, T. Nimmanwudipong, D. E. Block and B. C. Gates, Energy Fuels, 2011, 25, 47764785.

33 M. Arshadi, A. R. Faraji and M. J. Amiri, Chem. Eng. J., 2015, 266, 345-355.

34 K. S. W. Sing, D. H. Everett, R. A. W. Haul, L. Moscou, R. A. Pierotti, J. Rouquerol and T. Siemieniewska, in Handbook of Heterogeneous Catalysis, Wiley-VCH Verlag $\mathrm{GmbH}$ \& Co. KGaA, 2008, DOI: 10.1002/9783527610044.hetcat0065.

35 H. Long, Y. Xu, X. Zhang, S. Hu, S. Shang, Y. Yin and X. Dai,J. Energy Chem., 2013, 22, 733-739.

36 N. Rahemi, M. Haghighi, A. A. Babaluo, M. F. Jafari and S. Allahyari, Korean J. Chem. Eng., 2014, 31, 1553-1563. 
37 E. J. M. Hensen, D. G. Poduval, P. C. M. M. Magusin, A. E. Coumans and J. A. R. v. Veen, J. Catal., 2010, 269, 201-218.

38 E. Lovell, Y. Jiang, J. Scott, F. Wang, Y. Suhardja, M. Chen, J. Huang and R. Amal, Appl. Catal., A, 2014, 473, 51-58.

39 Y. Wang, J. Wu and S. Wang, RSC Adv., 2013, 3, 12635.

40 X. Zhang, J. Long, W. Kong, Q. Zhang, L. Chen, T. Wang, L. Ma and Y. Li, Energy Fuels, 2014, 28, 2562-2570.
41 J. Hong, W. Chu, P. A. Chernavskii and A. Y. Khodakov, J. Catal., 2010, 273, 9-17.

42 G. Yao, G. Wu, W. Dai, N. Guan and L. Li, Fuel, 2015, 150, 175-183.

43 Y.-C. Lin, C.-L. Li, H.-P. Wan, H.-T. Lee and C.-F. Liu, Energy Fuels, 2011, 25, 890-896.

44 C. R. Lee, J. S. Yoon, Y.-W. Suh, J.-W. Choi, J.-M. Ha, D. J. Suh and Y.-K. Park, Catal. Commun., 2012, 17, 54-58. 